\title{
IZQUIERDA DEMOCRÁTICA POPULAR. PODER POPULAR Y DEMOCRACIA DE BASE EN MÉXICO
}

\section{PopUlaR DeMOCRATIC LEFT. Popular PoWer AND GRASSROOTS DEMOCRACY In MeXICO}

Fecha recepción: 6 de octubre de 2021 / fecha aceptación: 15 de noviembre de 2021

\section{Ana Luisa Sánchez Hernández ${ }^{1}$}

\section{Cómo citar este artículo:}

Sánchez Hernández, A. L. (2021). Izquierda democrática popular. Poder popular y democracia de base en México. Revista Pensamiento y Acción Interdisciplinaria, 7(2), 10-26. https://doi.org/10.29035/pai.7.2.10

\section{Resumen}

Tras la muerte en combate de Lucio Cabañas, comandante de la Brigada Campesina de Ajusticiamiento del Partido de los Pobres, en 1974, la agrupación guerrillera experimentó diversas transformaciones y facciones, dando lugar una de ellas a la organización política, pacífica y de masas Izquierda Democrática Popular (IDP), la que se constituyó en 1999 después de la absolución y liberación de ocho excombatientes. La trayectoria de IDP deja en evidencia las debilidades del sistema de representación democrática en México. El asedio constante del Estado, a lo largo de cinco décadas, a sus fundadores y principales actores mediante prácticas legales, paralegales e ilegales, que han atentado contra sus derechos humanos, muestra la necesidad de expresiones democráticas alternativas a la democracia institucional. A partir del trabajo etnográfico con Izquierda Democrática Popular se dará cuenta de cómo su experiencia atestigua la posibilidad de tomas de decisiones y prácticas comunitarias promovidas a partir de los espacios cotidianos donde se reside, se trabaja, se estudia y se moviliza, es decir, de una democracia de base, en estrecha relación con el territorio, en la que se reivindica a la comunidad como el lugar crítico de la transformación social.

Palabras clave: democracia, Izquierda Democrática Popular, Partido de los Pobres, poder popular, trabajo de base

1 Doctora en Creación y Teorías de la cultura, UDLAP, México. Actualmente, profesora del Departamento de Estudios Humanísticos del Tecnológico de Monterrey Campus Puebla. Correo electrónico: analu.sanchezhz@udlap.mx 


\begin{abstract}
After the death in combat of Lucio Cabañas, commander of the Peasant Brigade of Execution of the Party of the Poor in 1974, the guerrilla group experienced diverse transformations and factions, giving rise one of them to the political and pacific organization of masses Left Popular Democratic Party (IDP), which was constituted in 1999 after the acquittal and liberation of eight ex-combatants. The IDP trajectory evidences the weaknesses of the system of democratic representation in Mexico. The constant siege of the State throughout five decades to its founders and main actors by means of legal, paralegal and illegal practices that have attempted against their human rights shows the necessity of alternative democratic expressions to the institutional democracy. Drawing from the ethnographic fieldwork with Popular Democratic Left, this paper will provide an account of how its experience testifies the possibility of decision makings and communitarian practices that emerge in the daily spaces where people live, work, study and mobilize, that is to say, of a grassroots democracy, in near relation with the territory, in which community is vindicated as the critical place of social transformation.
\end{abstract}

Keywords: democracy, grassroots organizations, Party of the Poor, Popular Democratic Left Party, popular power

\title{
Introducción
}

El 19 de mayo de 1967, tras la masacre de civiles que se reunían en el zócalo de Atoyac de Álvarez, Guerrero, Lucio Cabañas, maestro rural, su hermano David y un par de hombres más tomaron las armas y subieron a la sierra para conformar el Partido de los Pobres (PDLP) y su brazo armado, la Brigada Campesina de Ajusticiamiento (BCA). Esta decisión no fue del todo espontánea: durante sus viajes como dirigente de la Federación de Estudiantes Campesinos Socialistas de México, Lucio Cabañas había tenido contacto con el Partido Comunista Mexicano y con los hermanos Gámiz y Gaytán de Chihuahua, quienes habían conformado el Grupo Popular Guerrillero y asaltado el cuartel militar de Madera en 1965. Lucio Cabañas había participado, además, en la lucha encabezada por Genaro Vázquez y la Asociación Cívica Guerrerense, que había llevado a la destitución del gobernador de Guerrero, Raúl Caballero Aburto, tras la represión al movimiento estudiantil el 30 de diciembre de 1960 en la Alameda de Chilpancingo. Asimismo, su trabajo al lado del también maestro Serafín Núñez había posibilitado la integración de gran cantidad de profesores de la Costa Grande de Guerrero al Movimiento Revolucionario del Magisterio (MRM), y juntos habían dirigido grandes concentraciones en Atoyac para exigir un precio justo por el café y el ajonjolí y créditos y seguros para la construcción de escuelas, carreteras y servicios públicos (López Limón, 2009). Lucio Cabañas, por tanto, sabía que en algún momento sería reprimido y que entonces sería el momento de abandonar la lucha pacífica. Aquel día de mayo logró escapar con la protección de varias mujeres que lo cubrieron mientras los policías judiciales disolvían con balas el mitin en el que fueron asesinados cinco civiles. 
Durante siete años, Lucio y David Cabañas y decenas más de hombres y mujeres permanecieron en las montañas de Atoyac, luchando por la revolución socialista siguiendo el método guerrillero. La consigna del PDLP -"Ser pueblo, hacer pueblo, estar con el pueblo"-guió el actuar de los militantes del partido y la brigada: debían estar en contacto con los campesinos, aprender de ellos y visitar cada poblado para levantar el espíritu de los pobres, para que confiaran en la unión del pueblo y se le arrebatara al enemigo, la clase rica, el dinero y las armas.

El 2 de diciembre de 1974, luego de seis meses de una intensa ofensiva del Estado mexicano contra el PDLP-BCA, Lucio Cabañas murió en combate. Dieciocho de los 48 combatientes que conformaban la columna principal de la BCA habían caído tres meses antes. Las comunidades por donde habían pasado los guerrilleros fueron arrasadas por el ejército; algunos militantes sobrevivientes bajaron a la ciudad para trabajar y subsistir. Quienes insistieron en la lucha fueron dispersados, y las autoridades proclamaron que, con la muerte de Lucio, la guerrilla en Guerrero había sido derrotada. Los escasos estudios históricos sobre la reconfiguración del Partido de los Pobres tras el fallecimiento de su líder reforzaron esta idea.

Mas el PDLP-BCA no dejó de existir. Su organización política, sin embargo, cambió rápidamente. Las comisiones de lucha desaparecieron y se perdieron las bases de apoyo campesinas; la estructura partidaria, que era rural, se hizo urbana y altamente selectiva y vanguardista (Silva, 2015) y dio lugar a posteriores alianzas, transformaciones y facciones que originaron diversos grupos que continuaron reivindicando la lucha armada y otros, como Izquierda Democrática Popular, que se autodefinió como una organización "democrática, pacífica y de masas que actuará dentro de los marcos constitucionales" (Izquierda Democrática Popular, s.f.). Las características de esta organización, su proyecto y reivindicaciones, así como algunas de las implicaciones que supone la constitución de IDP para la institucionalidad democrática son las consideraciones del presente artículo².

\section{Marco referencial}

Para finales de los 70, los movimientos armados en México se encontraban debilitados (Castellanos, 2016; Jiménez, 2019). No obstante, diversas agrupaciones "habían logrado resonancia en la opinión pública con acciones revolucionarias aisladas, secuestros de alto impacto y robo de bancos" (Jiménez, 2019). El año 1978 fue particularmente notable. En enero entró en vigor la Ley de Organizaciones Políticas y Procesos Electorales (LOPPE), que permitió la integración de partidos políticos de izquierda en las contiendas electorales y el 18 de julio la Cámara de Diputados aprobó la ley de amnistía:

A favor de todas aquellas personas en contra de quienes se haya ejercitado acción penal, ante los tribunales de la Federación

\footnotetext{
2 Para la elaboración de este artículo se recuperaron los datos recabados durante el trabajo de campo emprendido entre 2018 y 2020 con la organización Izquierda Democrática Popular, el que incluyó entrevistas a algunos de sus miembros, participación observante y netnografía.
} 
o ante los tribunales del Distrito Federal en materia de fuero común, hasta la fecha de entrada en vigor de la presente ley, por los delitos de sedición, o porque hayan invitado, instigado o incitado a la rebelión, o por conspiración u otros delitos cometidos formando parte de los grupos impulsados por móviles políticos con el propósito de alterar la vida institucional del país, que no sean contra la vida, la integridad corporal, terrorismo o secuestro [...] condicionada a la entrega de todo tipo de instrumentos, armas, explosivos, u otros objetos empleados en la comisión de los delitos, dentro del plazo de 90 días a partir de la vigencia de esta Ley. (Diario Oficial de la Federación, 1978)

Asegura Sierra Guzmán (2003) que en la Costa Grande de Guerrero esta ley alivió buena parte de la tensión que se generó tras la muerte de Lucio Cabañas y cooptó a una parte de los sobrevivientes de la guerrilla. El 13 de agosto de 1978, Miguel Nazar Haro 3 asumió la dirección de la DFS, por lo que muchos integrantes de distintas organizaciones rechazaron la aministía. Grupos como la LC23S y Unión del Pueblo (UP) no suspendieron sus acciones; ese año UP hizo estallar cerca de 30 bombas en la Ciudad de México, Oaxaca y Guadalajara, causando pérdidas por más de 300 millones de pesos; se articuló, además, al conflicto universitario de la Universidad Autónoma Benito Juárez de Oaxaca (Jiménez, 2019) y continuó publicando su periódico Proletario.

En 1979, UP se transformó en el Partido Revolucionario Obrero Clandestino Unión del Pueblo (PROCUP). Carlos Montemayor (2007) aseguraba que PROCUP fue "una de las organizaciones guerrilleras más sobresalientes y constantes", cuyo rasgo distintivo fue el manejo de explosivos de manera tal que no provocaran daños en vidas humanas, sino únicamente en instalaciones estratégicas. En 1990, el general Mario Arturo Acosta Chaparro -posteriormente acusado por delitos de lesa humanidad y por nexos con el narcotráfico4- consideraba al PROCUP como "la organización más peligrosa en México, sobre todo por [...] el terrorismo y sabotaje contra instalaciones militares, así como de oficinas y dependencias de los gobiernos estatales y federal, incluyendo también a empresas particulares en varios estados del país" (Montemayor, 2007, p. 1).

El lineamiento político de PROCUP era la guerra popular prolongada y, a través de ella, buscaba la incorporación de las masas a la causa. Con el fin de lograr la unidad revolucionaria, PROCUP entró en contacto con los sobrevivientes del PDLP a inicios de la década de 1980. Buscaban conocerse, intercambiar experiencias y discutir sobre marxismo para definir coincidencias y establecer la coordinación entre las organizaciones socialistas (PDPR-EPR, s.f.).

\footnotetext{
3 Miguel Nazar Haro recibió adiestramiento antiguerrilla en la Escuela de las Américas y en la Zona del Canal de Panamá. Fue "partícipe directo en la tortura y desaparición de opositores políticos al régimen, fue además fundador de la Brigada Blanca, organización paramilitar encargada de aniquilar a la guerrilla urbana" (López de la Torre, 2013).

4 En 2008 Arturo Acosta Chaparro fue exonerado de los delitos y un año más tarde, durante el sexenio de Felipe Calderón, se retiró con honores. Fue asesinado el 20 de abril de 2012 en la Ciudad de México (Cruz y Becerril, 2012).
} 
De acuerdo con el PDPR-EPR (s.f.), entre 1981 y 1982 se concretó un trato de seis años para que los sobrevivientes del PDLP se integraran al PROCUP y se decidió que, para reinvindicar su experiencia en la selva de Guerrero y para honrar la memoria de Lucio Cabañas, el partido cambiaría su nombre. Bajo esta unión:

Se elaboró la experiencia y se masificó publicando el libro EI PDLP, una experiencia guerrillera en México [en 1987], y el nombre del partido cambió de PROCUP a PROCUP-PDLP. [...] Ciertamente desde la militancia se asume la unidad, pero de quienes tenían función de responsables algunos nunca dejaron de ser PDLP, siempre preservaron su origen, por consecuencia la unidad para ellos sólo [sic] era alianza y se encomiaba el origen del PDLP como forma de reclutamiento. (PDPR-EPR, s.f., p. 341)

En 1986, integrantes del PROCUP-PDLP fueron entrevistados por Mario Menéndez Rodríguez de la Revista Por esto! como organizaciones distintas, lo que -dijeron algunos- "nos costó mucho trabajo realizar las del PDLP porque había que contestar como si no fuéramos ya un solo partido" (PDPR-EPR, s.f., p. 307). Sin embargo, para algunos otros miembros de PROCUP:

Se detectó un terrible regionalismo, la defensa a ultranza de Lucio Cabañas Barrientos (LCB) sin análisis, una actitud más emotiva que racional, teniendo como referente máximo el haber echado balazos en la sierra contra el ejército mexicano [...] Desde el 84-85 ya se veía venir un problema en algunos compañeros que se tomaron en serio la existencia de dos partidos, pero se dejó crecer y no se acotó esta actitud en su momento. Aquí están las raíces de la incomprensión de la unidad, de la simulación y nuestra incapacidad para detener dicho proceso [localista]. (PDPR-EPR, s.f., pp. 402-403)

PROCUP-PDLP siguió trabajando con la clase campesina y con comunidades be'ene zaa, tu'un savi, nahua, ódami, ralámuri, bats'il winik otik y winik atel de diversos lugares de la República. En 1990 el partido detonó bombas tras la desaparición forzada de David Cabañas, Felipe Canseco y Ana María Vera Smith para exigir su presentación con vida. Los siguientes cuatro años, a partir del documento Tareas y objetivos en la presente etapa, PROCUP-PDLP se preparó para el reinicio de las hostilidades militares, la obtención de fondos y la construcción de zonas guerrilleras y del frente nacional de masas.

El levantamiento del EZLN en enero de 1994 aceleró sus planes. Se organizaron reuniones nacionales conocidas como "consejos de representantes" de las que surgieron los objetivos y las tareas estratégicas que se tomarían a partir del siguiente año. El 3 de junio de 1994, el PROCUP-PDLP emitió un comunicado interno de presentación de su Ejército Popular Revolucionario (EPR) con el lema 
"Por la revolución socialista, vencer o morir" y la consigna “iCon la guerra popular, el EPR triunfará!" (Camacho, 2013).

Al año siguiente, en el vado de Aguas Blancas, el gobierno de Guerrero, con Rubén Figueroa Alcocer al frente, masacró a integrantes de la Organización Campesina de la Sierra Sur, lo que propició la formalización del EPR. El 28 de junio de 1996 más de cien hombres y mujeres del PROCUP-PDLP se presentaron en el vado durante la conmemoración del primer aniversario de la masacre (Gutiérrez, 1996). Víctor Cardona, cronista de Guerrero, asegura que al verlos armados con rifles AK-47 corrió rumbo a una zanja: "Pensé que había caído el Ejército a masacrarnos" (Cardona, 2019, p. 3). No se podía dejar el lugar, "los hombres de gorras amarillas eran muchos y habían formado una cadena humana en torno a la concentración”, agrega Cardona (2019, p.3). Sin embargo, les aseguraban que eran compañeros y les pedían que no corrieran. Los integrantes del PROCUP-PDLP entregaron una ofrenda de plantas, rindieron honores a la bandera, dispararon 17 salvas en honor a los campesinos asesinados el año anterior y leyeron la Declaración de Aguas Blancas que constituiría la presentación pública del EPR y que manifestaba que habían decidido:

Cambiar nuestras herramientas de trabajo por los fusiles libertarios que habrán de combatir y contribuir al derrocamiento del gran capital y del gobierno antipopular [...] Nos planteamos luchar: 1) por el derrocamiento del gobierno antipopular, antidemocrático, demagógico e ilegítimo al servicio del gran capital nacional y extranjero y de las fuerzas que lo sostienen y por el establecimiento de un nuevo gobierno esencialmente distinto al que hoy detenta el poder; 2) por restituir la soberanía popular y los derechos fundamentales del hombre. Este objetivo lo lograremos, con la participación del pueblo y el establecimiento de una república democrática popular, ejerciendo el legítimo derecho del pueblo a alterar o modificar la forma de su gobierno; 3) por la solución a las demandas y necesidades inmediatas del pueblo, realizando los cambios económicos, políticos y sociales que se requieren; 4) por el establecimiento de relaciones justas con la comunidad internacional; 5) por el castigo a los culpables de la opresión política, represión, corrupción, miseria, hambre y crímenes de lesa humanidad cometidos contra el pueblo. (PDPR-EPR-TDR, 2002, p. 63)

Al día siguiente se dio un enfrentamiento entre el ejército mexicano y el EPR (Camacho, 2013; Silva, 2015). Hubo detenciones que llevaron a la confiscación de documentos de carácter estratégico y a discusiones internas debido a lo que algunos miembros del PROCUP-PDLP consideraron "tendencias localistas y peleas por el mando" (PDPR-EPR, s.f., p. 274). Durante algunas de las discusiones se había sugerido el cambio del nombre del partido como medida de seguridad y para evitar la estigmatización que el Estado había impuesto sobre PROCUP-PDLP, 
también para evitar el reduccionismo de incluir solamente a la clase obrera y no al pueblo en general (PDPR-EPR, s.f.).

El 7 de agosto de 1996, el PROCUP-PDLP dejó de existir y se dio a conocer el Manifiesto de la Sierra Madre Occidental, mediante el cual se hizo pública la aparición del Partido Democrático Popular Revolucionario (PDPR) y su programa político. Sus objetivos incluían la formación de un nuevo gobierno, una nueva constitución, la construcción de una república democrática popular y federal y un reordenamiento económico (Partido Democrático Popular Revolucionario Ejército Popular Revolucionario, 1996). En ese momento, ya no quedaba en el partido ninguno de los integrantes del Partido de los Pobres que se fundó en 1967. Lo que permanecía era la idea de Lucio Cabañas de que:

La hechura o la construcción o el formar partido es según se combata, en vista de que el trabajo político legal está prohibido en México. Entonces lo único que nos abre camino para construir un verdadero partido revolucionario es el combatir. Y aquella organización que no combata y se dedique nomás a hacer trabajos pacíficos, no va a construir el partido. Y se forma un partido, sus elementos no toman el temple, la formación revolucionaria que se requiere para esta época [...] el combate como principal forma de práctica. (citado en Suárez, 1976, p. 134)

Para entonces David Cabañas y otros militantes de PROCUP-PDLP se encontraban en prisión. Habían sido detenidos el 12 y el 13 de junio de 1990 y torturados y desaparecidos más de una semana. Las bombas que los rescataron explotaron el 18 de junio en la agencia Nissan de Oaxaca, donde quedaron esparcidos impresos del PROCUP-PDLP que exigían la presentación con vida de Felipe Edgardo Canseco, Ana María Vera Smith y David Cabañas:

Todos ellos fueron trasladados al Campo Militar Número 1 para continuar con la tortura física y psicológica, sin que hasta el momento hayan sido presentados. Aclaramos: no fue la capacidad de investigación de la policía política la que hizo posible estas detenciones [...] No pedimos para ellos indulgencia, sino apego al derecho y a la Constitución por parte del Estado Mexicano. Tenemos confianza en que el pueblo hará suya esta exigencia y luchará junto a nuestro Partido hasta la presentación pública de nuestros compañeros. Preguntamos: ¿cuál será ahora la actitud de aquellos que han negado nuestra existencia y han pedido la cabeza de los revolucionarios, y cuál será su opinión con respecto a que actuemos ojo por ojo, diente por diente? [...] Estas acciones son pequeñas en comparación con las que habremos de desarrollar hasta la presentación con vida de nuestros compañeros. (De pronto el Procup ya es un movimiento armado, s.f.) 
David Cabañas (comunicación personal, julio de 2018) considera que si hubiera sido detenido en el tiempo de la Guerra Sucia ${ }^{5}$ no hubiera aparecido, que lo hubieran matado de la peor manera. No obstante, también sabe que "el Estado no puede hacerle caso omiso a todo porque tiene muchos errores e incumple en muchas normas, así que hace cosas para enmascarar un poco cuando hay presión, le juegan al justiciero. Por eso cuentan mucho las organizaciones". La Comisión Nacional de Derechos Humanos (CNDH), dice, es producto de las presiones populares, lo mismo la Fiscalía Especial para Movimientos Sociales y Políticos del Pasado (FEMOSPP) y la Ley Federal de Organizaciones Políticas y Procesos Electorales (LOPPE). La Guerra Sucia, continúa, "ya había sido muy denunciada, ya había terminado la etapa de la desaparición brutal" (Cabañas, comunicación personal, julio de 2018).

Aun así, permaneció ocho años en la cárcel. Para algunos de sus compañeros de lucha el tiempo de encierro se extendió diez, doce y hasta dieciséis años. En la cárcel, junto con nueve presos más, ocho de ellos también exguerrilleros, fundó el Colectivo de Presos Políticos, la Comisión Interna de Derechos Humanos y, más tarde, la Coordinadora Nacional de Presos Políticos en México. Sus comisionados recorrieron las cárceles del país, recabando datos que se condensaron en reportes anuales. En abril de 1991 realizaron una conferencia de prensa, algo que no se había hecho nunca, para hacer públicas sus demandas y denuncias: papel, periódico, libros, cobijas, colchonetas. Realizaron plantones -el más grande con 300 presos comunes-. En 1996, David Cabañas fue trasladado al penal de máxima seguridad de Almoloya de Juárez, Io consideraban altamente peligroso; ahí formó parte del Comité de Familiares y Amigos de Presos Políticos y Sociales, quienes se movilizaron para solicitar visitas constantes de la Cruz Roja Internacional. Fue, finalmente, absuelto y puesto en libertad en 1998 y el 31 de enero de 1999 fundó formalmente, junto con algunos de sus compañeros de PROCUP-PDLP que también estuvieron presos, la organización Izquierda Democrática Popular (IDP)

\section{Resultados y discusión}

La fundación de IDP en 1999 coincidió con la llamada transición democrática en México. Aquel año resultó electo a la presidencia el candidato del PAN, Vicente Fox, después de derrotar al PRI que se había instalado como el partido hegemónico desde 1929. El "gobierno de la alternancia" emprendió medidas promisorias para la defensa de los derechos humanos, la justicia social y la democracia, como la creación del Instituto Nacional de las Mujeres y de la Fiscalía Especial para Movimientos Sociales y Políticos del Pasado (FEMOSPP), así como la transferencia de archivos de la Dirección Federal de Seguridad, de la Secretaría de la Defensa Nacional y de la Dirección General de Investigaciones Políticas y Sociales al Archivo

\footnotetext{
5 No hay un verdadero consenso sobre la periodización de la Guerra Sucia; sin embargo, diversos investigadores concuerdan que corresponde principalmente a los años que van de 1962 a 1982, durante los sexenios de Adolfo López Mateos, Gustavo Díaz Ordaz, Luis Echeverría y José López Portillo (Díaz Tovar, 2015; Kuri Pineda, 2017; Villareal Martínez, 2016). Herrera Calderón (2012) y Cedillo (2005) aseguran que el término "Guerra Sucia" es controversial y corresponde a una convención periodística; y Vicente Ovalle (2019) argumenta que es inadecuado, ya que oculta el uso de instrumentos legales para el combate a la disidencia política.
} 
General de la Nación para su acceso público. No obstante, asegura Marroquín Pineda (2021), los resultados fueron magros debido a la falta de dotación de facultades y capacidades técnicas ${ }^{6}$ de estas instancias. Aunado a esto, Fox reforzó la estrategia de seguridad-iniciada por Ernesto Zedillo- de capturar a los líderes de los cárteles del narco, estrategia que más tarde dio lugar a la "Guerra contra el narco" acometida por Felipe Calderón, y que dejó un saldo aproximado de 350 mil personas asesinadas y 70 mil personas desaparecidas para el 2012 (Pardo Veiras y Arredondo, 2021).

Más aún, los gobiernos panistas no rompieron el "legado autoritario de la represión" (Marroquín Pineda, 2021) del antiguo régimen, el que mantuvo su vigencia durante el regreso del PRI con Enrique Peña Nieto y se conserva aún en la actual administración morenista ${ }^{7}$ de Andrés Manuel López Obrador. De acuerdo con la propia Secretaría de Gobernación, en lo que va del gobierno de López Obrador han sido asesinados 43 periodistas y 68 defensores de derechos humanos (La Jornada, 2021) ${ }^{8}$. Asimismo, en el actual gobierno queda la profunda desconfianza hacia los partidos políticos, la continuación de los fundamentos económicos neoliberales, la incapacidad para enfrentar a las oligarquías y élites empresariales y el crónico vacío ideológico. Todos estos elementos, a decir de Tiziana Bertaccini y Carlos Illades (2021), han provocado una "transición democrática inacabada".

En este escenario de inconclusa democracia, y también de creciente violencia, es urgente considerar las trayectorias y procesos de organizaciones civiles que han insistido en la instauración democrática. La agrupación Izquierda Democrática Popular, cuyos fundadores otrora se levantaron en armas, realiza acciones sustanciales para la transformación política en México que conviene recalcar. Sobre la conformación de IDP, Ítalo Ricardo Díaz Díaz (citado en Lo que es preocupante es que va eliminando los cauces pacíficos por un cambio social en México, s.f.), exmiembro de PROCUP-PDLP, menciona:

Cuando nosotros salimos de la cárcel, en el escenario político nacional no existe una alternativa política en la que nosotros nos sintamos representados. Son momentos difíciles en el país, se están consolidando algunas estructuras en el ámbito electoral como el PRD y nosotros estamos saliendo a un escenario totalmente distinto de aquel que vivimos previamente a caer en la cárcel. La Guerra Fría ha terminado, estamos en un escenario mundial de carácter unipolar donde los Estados Unidos imponen a su voluntad lo que quieren, y adicionalmente tenemos que

\footnotetext{
6 Como ejemplo, se puede nombrar al expresidente Luis Echeverría que fue acusado por la FEMOSPP en dos ocasiones por genocidio y desaparición forzada, y cuyos casos fueron rechazados y cerrados.

7 Andrés Manuel López Obrador llegó a la presidencia como candidato del Movimiento de Regeneración Nacional (MORENA) en 2018. En 2006 y 2012 fue candidato a la presidencia por el Partido de la Revolución Democrática (PRD), quedando en segundo lugar frente al PAN y el PRI, respectivamente.

8 En el sexenio de Peña Nieto las cifras fueron de 161 defensores y 40 periodistas asesinados (Agencia EFE, 2018). Por su parte, Artículo 19 (2021) cuenta 61 luchadores sociales y 48 periodistas asesinados durante la administración de Calderón y 22 periodistas asesinados en el gobierno de Fox.
} 
en América del Sur comienza a abrirse una nueva ruta, para la lucha social y para el desarrollo de los movimientos socialistas en América Latina. (2:28')

Tres años después de su fundación, el 31 de enero de 2002, Izquierda Democrática Popular buscó su registro ante el Instituto Federal Electoral (IFE); sin embargo, el 17 de abril de ese mismo año, el Consejo General del IFE emitió la resolución CG19/2002 que estipuló que "no procede el otorgamiento del registro como Agrupación Política Nacional, a la asociación de ciudadanos denominada Izquierda Democrática Popular [...] toda vez que no cumple con lo dispuesto" en el Código Federal de Instituciones y Procedimientos Electorales. Esto debido a que a los 9004 afiliados que presentó IDP le fueron restadas las "inconsistencias" y las personas que estaban también afiliadas a otras asociaciones, aprobando el IFE únicamente un total de 6572 asociados a IDP: insuficientes para cumplir con el requisito de siete mil. El 11 de junio, los magistrados de la Sala Superior del Tribunal Electoral del Poder Judicial de la Federación confirmaron por unanimidad la resolución del Consejo General (Consejo General del Instituto Federal Electoral, 2002). Para Díaz Díaz (citado en Lo que es preocupante es que va eliminando los cauces pacíficos por un cambio social en México, s.f.), tales resoluciones fueron subterfugios legales que acompañaron a otros argumentos que buscaban estigmatizarlos por sus procedencias políticas, además de acusarlos de ser "el brazo político de la insurgencia en México" de aquella época.

Insistieron, por tanto, los miembros de IDP en que su lucha se estaba desarrollando en el terreno de la política de masas, con herramientas legales y en el ejercicio de sus libertades constitucionales y sus derechos humanos. Díaz Díaz (citado en Lo que es preocupante es que va eliminando los cauces pacíficos por un cambio social en México, s.f.) declaró de manera contundente: "Cuando estuvimos en la cárcel nosotros decidimos asumir que habíamos cambiado nuestra trinchera de lucha, y que en la que nos encontrábamos a partir de entonces era una trinchera de la dignidad"(13:56'). Hermenegildo Torres, también expreso político, comentaba de forma parecida: "La estructura rígida del PROCUP la analizamos a fondo desde la cárcel. Iniciamos el cuestionamiento interno, nos preparamos mentalmente para ya no caminar con la pistola fajada" (El siglo de Torreón, 2007).

Dentro de la cárcel, donde se concibió la organización, continúa Díaz Díaz (citado en Lo que es preocupante es que va eliminando los cauces pacíficos por un cambio social en México, s.f.), definieron cuatro líneas de su quehacer: "La primera fue mantenernos vivos. Para esto era muy importante la cohesión del colectivo de presos políticos, el cuidado mutuo, la prudencia y la organización interna, es decir, nos mantuvimos como un ente organizado dentro de la prisión" (14:18'). La segunda constituyó en contener, en lo posible, los abusos que se cometían contra los presos comunes y denunciarlos. El tercer eje fue "hacer de la cárcel una caja de resonancia" de sus posiciones políticas, colaborando con defensores de derechos humanos que los visitaban y llevaban al exterior de la cárcel sus comunicaciones y posicionamientos políticos. Finalmente, se concentraron en producir testimonios 
y documentación de la problemática de la cárcel y del sistema judicial en los ámbitos de la procuración, la administración y la impartición de justicia, dando como resultado, entre otros textos, Los tres círculos del infierno de Dante, los que contenían testimonios, transcripciones de grabaciones y estadísticas.

En 1999, la Izquierda Democrática Popular publicó sus tesis y principios, orientados a:

La construcción de una verdadera república democrática donde tengan plena vigencia el respeto a las libertades políticas, la división de poderes, el sufragio popular, la participación de todos los ciudadanos en la toma de decisiones trascendentes para la vida nacional, de las comunidades y sectores sociales y el respeto irrestricto a los derechos humanos. (p. 6)

De este modo, IDP plantea como sus principios ideológicos la construcción de una sociedad más justa y de un nuevo orden económico internacional equitativo; la pugna por el real funcionamiento del régimen democrático y la constitución de una mesa de diálogo nacional para construir el poder popular; el impulso de los niveles de salud y educación de toda la sociedad mexicana, así como el fomento del respeto a la diversidad, los derechos, la cultura y la autonomía de los diferentes grupos étnicos e indígenas del país. Su plan de acción, integrado por 59 puntos, incluye, en lo económico, el fomento de nuevas formas sociales de producción, comercialización y consumo; el fin de la privatización de empresas paraestatales; el restablecimiento de formas comunales y colectivas de propiedad de la tierra y la promoción de la autosuficiencia alimenticia. Además, sus acciones sociales se dirigen a la lucha por un salario digno y en contra del desempleo, la promoción de programas de atención a la niñez y de formación técnica, científica y estética a todos los sectores de la población, y la promoción de un sistema de salud único, solidario, gratuito y de cobertura universal, entre otros. Finalmente, en el ámbito político, busca principalmente la lucha contra el corporativismo gubernamental; la procuración e impartición de justicia con apego a derecho; el recorte presupuestal al ejército, a las fuerzas de seguridad pública y a las campañas electorales; la erradicación de bandas paramilitares y la lucha por la presentación con vida de los detenidos-desaparecidos.

Las tesis de IDP constituyen una actualización y enriquecimiento de sus principios. En ellas quedan expresadas las crisis de los Estados-nación, la necesidad del internacionalismo proletario y la búsqueda de una alternativa al neoliberalismo y de una autonomía con todo y sus implicaciones territoriales y de usufructo. Cabe enfatizar la novena tesis que nombra los "logros en la historia reciente de México", entre los que cita la repulsa contra las soluciones militares del Estado, la exhibición de la corrupción interna de los gobiernos y la consecuente disminución del prestigio y autoridad del poder ejecutivo, así como la apertura de la cámara legislativa a los partidos de oposición. Aunado a esto, se plantea al socialismo como una necesidad histórica, la que depende de la orientación del poder del pueblo 
para alcanzarlo. La construcción de este poder, pues, requiere de la incorporación al sujeto histórico de "los grupos sociales crecientemente empobrecidos por la globalización, tales como los pequeños y medianos empresarios quebrados y desplazados, los deudores de la banca, los desempleados y jubilados, los vendedores ambulantes y los trabajadores migrantes" (Izquierda Democrática Popular, 1999, p. 11).

En el número más reciente de su publicación Poder Popular, Izquierda Democrática Popular (2021) hace especial énfasis en el asedio que el Estado y algunos medios han lanzado sobre la organización, como la detención de Hermenegildo Torres Cruz después del sabotaje a ductos de PEMEX en 2007 reivindicado por el Ejército Popular Revolucionario como respuesta a la desaparición forzada de dos de sus integrantes, la acusación sobre Constantino Alejandro Canseco Ruiz de ser el autor del secuestro del político Diego Fernández de Cevallos en 2010, y el asesinato de Ricardo Mejía Samaniego en 2016 debido al trabajo de base que realizaba en zonas controladas por Antorcha Campesina. A esto se puede agregar la denuncia que realizó IDP en el Correo llustrado del periódico La Jornada del 20 de agosto de 2015 por intimidación y amenaza por parte del régimen estatal a David Cabañas luego de que el 6 de agosto de ese año dos hombres que se identificaron como agentes de la Procuraduría General de la República se presentaron en su casa y lo cuestionaron sobre su hermano Manuel, detenido-desaparecido desde 1974. Asimismo, las revelaciones en 2021 sobre el uso del software de espionaje Pegasus dejaron constancia de la vigilancia estatal a David Cabañas (Tourliere, 2021), y los constantes señalamientos contra Felipe Edgardo Canseco Ruiz en su actual función como suplente del alcalde de la ciudad de Oaxaca también son evidencia de la estigmatización de los miembros de IDP como guerrilleros, equiparando el término con el de secuestrador y terrorista (Excelsior, 2021).

De represión y hostigamiento, pues, les han pasado cincuenta años a los antiguos militantes del PROCUP-PDLP que conforman Izquierda Democrática Popular, quienes tras abandonar las armas insisten ahora que "la única vía para la transformación profunda del país debe ser pacífica” (Canseco Ruiz citado en Vega Aguilar, 2019). Mediante el trabajo con distintos colectivos de poder popular (CPP), sectores de trabajo, áreas de influencia política y jóvenes que se han incorporado a la organización, han planteado la necesidad de la formación político-ideológica con el objetivo de implantar el "embrión de una sociedad socialista aun dentro de las entrañas del capitalismo" (Izquierda Democrática Popular, 2021). Así, Ilevan a cabo actividades como el más reciente apoyo, mediante mítines y conferencias, a la Escuela Secundaria Popular Felipe Carrillo Puerto ante el desalojo de quienes encabezan el proyecto educativo popular y gratuito o las también actuales movilizaciones en demanda de mejoramiento de alumbrado público y equipamiento para las escuelas en conjunto con otros colectivos de los poblados de San Andrés, San Cristóbal y San Diego del norte de Toluca, así como las asambleas comunales en esta misma zona -donde Ítalo Díaz Díaz es director de una escuela secundaria- para determinar estrategias de exigencia de seguridad (Ríos, 2021) y 
para la convocatoria de participación y organización a vecinos y familiares frente a las agresiones del crimen organizado y las empresas privadas en colusión con las autoridades locales y las fuerzas armadas (Mercado y Alvarado, 2021). En su lema ¡iPor la patria, el poder popular!!, Izquierda Democrática Popular condensa su interés en constituir nuevas relaciones sociales y económicas a partir del trabajo de base. En este sentido, la estructura y las intenciones de IDP se asemejan a lo que identificaba Michael Kaufman (1997) en torno del poder comunitario y la democracia de base, donde lo principal es la organización a nivel comunitario, generalmente en el territorio en que los miembros de los colectivos viven y laboran, y con base en las necesidades comunes. Luego, el propósito se torna en atraer más poder hacia las comunidades de base $y$, de este modo, fomentar la politización, el estudio y la formación militante. Aunado a esto, cabe recalcar el potencial subversivo que tiene la dignidad para los integrantes de IDP: David Cabañas lo sintetizaba en su respuesta a un elogio por su valentía: "No se trata de valor, se trata de dignidad [...] porque para ser digno hay que tomar decisiones de vida o muerte". Para ellos, la dignidad, igual que el proyecto liberador, no se vende.

\section{Conclusiones}

La trayectoria de IDP deja en evidencia ciertas características del sistema de representación democrática en México. El asedio constante del Estado a lo largo de cinco décadas a sus fundadores y principales actores mediante prácticas legales, paralegales e ilegales, que han atentado contra sus derechos humanos, muestra la necesidad de expresiones democráticas alternativas ${ }^{9}$ a la democracia institucional. Lo que se ha señalado como una democracia fallida o "inacabada", en México pareciera ser un vigoroso sistema reproductor del sexismo, el clasismo y el autoritarismo que funciona a través de las jerarquías, la competencia y la exclusión que impone el régimen de partidos políticos. En este contexto, IDP, de manera colectiva, y varios de sus miembros, de forma individual ${ }^{10}$, se han encontrado en un constante vaivén entre la protesta social y la institucionalización política. Si bien ha cesado la búsqueda de registro como agrupación política, algunos de sus miembros se han incorporado a partidos enlistados oficialmente, mientras que otros, tras el hastío que les supone la indiferencia e ineficiencia de los funcionarios públicos, apuestan por una organización autónoma y autodefensiva.

La democracia, de este modo, no puede definirse en los términos institucionales existentes de los gobiernos capitalistas neoliberales. Tiene que ver con la extensión de la participación y la toma de decisiones a las poblaciones empobrecidas, con el acceso de las masas a los medios para definir en sus propios términos su actividad política y orientar sus destinos. La experiencia de Izquierda Democrática Popular atestigua la posibilidad de tomas de decisiones y prácticas comunitarias promovidas a partir de los espacios cotidianos donde se reside, se

9 O incluso de expresiones alternativas a la democracia.

10 Es necesario analizar en futuros estudios la participación diferenciada en la organización de acuerdo al género, edad, trayectoria política, clase, etc., de los miembros. 
trabaja, se estudia y se moviliza, es decir, de una democracia de base, en estrecha relación con el territorio que se habita.

Además, aquí resulta fundamental la acumulación de experimentos de organización comunitaria. En IDP confluyen las memorias y saberes de las resistencias y luchas rurales socialistas del Partido de los Pobres de la segunda mitad del siglo XX que, con su método asambleario y su énfasis en los pobres como sujetos revolucionarios, trastocaron el modelo marxista europeo, colocando a uno de los sectores más estigmatizado, vulnerado y abandonado como el nuevo sujeto histórico revolucionario y reivindicando a la comunidad como el lugar crítico de la transformación social.

\section{Referencias bibliográficas}

Agencia EFE. (29 de noviembre de 2018). Más de 200 defensores de DDHH y periodistas asesinados en sexenio de Peña Nieto. https://www.efe.com/efe/ america/mexico/mas-de-200-defensores-ddhh-y-periodistas-asesinados-ensexenio-pena-nieto/50000545-3828669

Artículo 19. Periodistas asesinadas/os en México, en relación con su labor informativa. https://articulo19.org/periodistasasesinados/

Bertaccini, T. e Illades, C. (2021). Partidos políticos y transiciones inacabadas en América Latina. Millars. Espai I Història, 1(50), 9-15. https://www.e-revistes. uji.es/index.php/millars/article/view/6011

Cabañas, David. (s.f.). Testimonio de David Cabañas Barrientos, sobreviviente de la guerrilla del Partido de los Pobres (PDLP). Ediciones Movimiento Democrático Independiente.

Camacho, Z. (24 de abril de 2013). Jacobo Silva Nogales: Aguas Blancas, el epicentro de una revolución. Contralínea. https://www.contralinea.com.mx/archivorevista/2013/04/24/jacobo-silva-nogales-aguas-blancas-el-epicentro-deuna-revolucion/

Cardona, V. (7 de enero de 2019). Crónicas del Palacio XIII. El Sur. https://suracapulco.mx/cronicas-del-palacio-xiii/

Castellanos, L. (2016). México armado. 1943-1981. Ediciones Era.

Cedillo, A. (2005). La "Guerra Sucia" en México. Represionmx. https://represionmx.wordpress.com/2011/08/10/la-guerra-sucia-en-mexico

Consejo General del Instituto Federal Electoral. (11 de junio de 2002). Juicio para la protección de los derechos político-electorales del ciudadano. https://www.te.gob.mx/colecciones/sentencias/html/SUP/2002/JDC/SUPJDC-00058-2002.htm 
Cruz, F. y Becerril, A. (21 de abril de 2012). Asesinan al General Mario Arturo Acosta Chaparro en la Ciudad de México. Excelsior. https://www.excelsior.com.mx/2012/04/21/nacional/828195

Díaz Tovar, A. (2015). Prácticas de Conmemoración de la Guerra Sucia en México. Athenea Digital, 15(4),197-221. https://raco.cat/index.php/Athenea/article/ view/303290

Diario Oficial de la Federación (1978). Ley de Aministía. https://www.dof.gob.mx/ nota_detalle.php?codigo $=4732307 \&$ fecha $=28 / 09 / 1978 \&$ print $=$ true

El siglo de Torreón (9 de octubre de 2007). Ayer guerrilleros, hoy vigilados por militares. https://www.elsiglodetorreon.com.mx/noticia/303006.ayerguerrilleros-hoy-vigilados-por-militares.html

Emanuelsson, D. y Emanuelsson, M. (2015). "Lo que es preocupante es que va eliminando los cauces pacíficos por un cambio social en México". Entrevista con miembros de la Dirección Nacional de la Izquierda Democrática Popular de México [Archivo de video]. https://www.youtube.com/ watch?v=VeLrVMIVoFk\&t=163s

Excelsior (1 de junio de 2021). Con exguerrilleros y activistas de la APPO, Francisco Martínez, busca la alcaldía de Oaxaca. https://www.excelsior.com.mx/ nacional/con-exguerrilleros-y-activistas-de-la-appo-francisco-martinezbusca-la-alcaldia-de-oaxaca

Gutiérrez, M. (29 de junio de 1996). Irrumpe grupo armado en Aguas Blancas. La Jornada. https://www.jornada.com.mx/1996/06/29/EPR00-2806.html

Herrera Calderón, F. (2012). Contesting the State from the Ivory Tower: Student Power, Dirty War and the Urban Guerrilla Experience in Mexico, 1965-1982. The University of Minnesota.

Izquierda Democrática Popular (2021). Poder Popular, (3). https://www.yumpu. com/es/document/read/65810792/revista-poder-popular-3

Izquierda Democrática Popular (1999). Declaración de Principios y Tesis.

Izquierda Democrática Popular (s.f.). Izquierda Democrática Popular. https://izquierdademocraticapopular.blogspot.com/

Jiménez, A. (7 de julio de 2019). 25 años del EPR: Desde la trinchera leninista. El Sol de Hidalgo. https://www.elsoldehidalgo.com.mx/mexico/politica/25anos-del-epr-desde-la-trinchera-leninista-guerrilla-guerrero-3856587.html

Kaufman, M. (1997). Community Power, Grassroots Democracy, and the Transformation of Social Life. En Kaufman, Michael y Dilla Alfonso, Harold (Eds.), Community Power and Grassroots Democracy. The Transformation of Social Life, Zed Books. 
Kuri Pineda, E. (2017). Espacio, "guerra sucia” y memoria. La construcción del museo Casa de la Memoria Indómita. Revista de Ciencias Sociales, (31), 115133. http://ridaa.unq.edu.ar/handle/20.500.11807/1679

La Jornada (13 de julio de 2021). Asesinados, 68 defensores de derechos humanos y 43 periodistas: Segob. https://www.jornada.com.mx/notas/2021/07/13/politica/ asesinados-68-defensores-de-derechos-humanos-y-43-periodistas-segob/

López de la Torre, S. (2018). Guerras secretas: memorias de un ex-guerrillero de los setentas que ahora no puede caminar. Sextil Online.

López Limón, A. G. (2009). Lucio Cabañas Barrientos y el Partido de los Pobres. http://investigacionesrubenjaramillomenez.blogspot.mx/2009/04/luciocabanas-barrientos-y-el-partido.html

Marroquín Pineda, T. I. (2021). El ejercicio impune de la represión política como legado autoritario y su incidencia en el cambio político y la calidad democrática en México. Contextualizaciones Latinoamericanas, 14(25) https://doi.org/10.32870/cl.v2i25.7869

Mercado, R. y Alvarado, M. (9 de octubre de 2021). "Tuvimos que meditarlo mucho tiempo, en horas de la noche". Viceversa Noticias. http://viceversanoticias. com/2021/10/09/tuvimos-que-meditarlo-mucho-tiempo-en-horas-de-lanoche/

Montemayor, C. (15 de julio de 2007). EPR. La Jornada. https://www.jornada.com. $\mathrm{mx} / 2007 / 07 / 15 /$ index.php?section=politica \&article=008a1 pol

Pardo Veiras, J. L. y Arredondo, I. (14 de junio de 2021). Una guerra inventada y 350,000 muertos en México. The Washington Post. https://www. washingtonpost.com/es/post-opinion/2021/06/14/mexico-guerranarcotrafico-calderon-homicidios-desaparecidos/

PDPR-EPR. (s.f.). 50 años de Lucha Armada Revolucionaria. https://www.academia. edu/34550806/F1286_P37_2016_PDPR_EPR_50_a\%C3\%B10s_de_lucha_ armada_revolucionaria

PDPR-EPR-TDP. (2002). Comunicados. Pueblo en Lucha. Junio de 2002.

Ríos, A. (21 de noviembre de 2021). Marchan en Toluca contra la inseguridad de la zona norte. https://lajornadaestadodemexico.com/marchan-en-tolucacontra-la-inseguridad-de-la-zona-norte-2/

Sierra Guzmán, J. L. (2003). El enemigo interno. Contrainsurgencia y fuerzas armadas en México. Centro de Estudios Estratégicos de América del Norte.

Silva, J. (2015). Lucio Cabañas y la guerra de los pobres. Deriva Negra-Cooperativa Rizoma.

Suárez, L. (1976). Lucio Cabañas. El guerrillero sin esperanza. Roca. 
Tourliere, M. (18 de junio de 2021). El movimiento social bajo estricta vigilancia. Proceso. https://www.proceso.com.mx/nacional/2021/7/18/el-movimientosocial-bajo-estricta-vigilancia-268035.html

Vega Aguilar, J. (20 de mayo de 2019). La única vía para la transformación del país debe ser pacífica. Real Politik. http://realpolitik.com.mx/la-unica-via-para-latransformacion-del-pais-debe-ser-pacifica/

Vicente Ovalle, C. (2019). [Tiempo suspendido] Una historia de la desaparición forzada en México, 1940-1980. Bonilla Artigas Editores.

Villareal Martínez, M. T. (2016). Desaparecidos. La lucha por la verdad y la memoria. Levadura. http://revistalevadura.mx/2016/01/10/desaparecidosla-lucha-por-la-verdad-y-la-memoria/

Dirección de correspondencia:

Ana Luisa Sánchez Hernández

Contacto: analu.sanchezhz@udlap.mx 